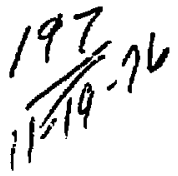

\title{
A 120-keV BEAM DIRECT CONVERSION SYSTEM FOR TFTR INJECTORS
}

JCRL-52137

\author{
G. W. Haxallton
}

September 21, 1976

\section{MASTER}

Prepared for U.S. Energy Research \& Developinent Administration under contract No. W-7405-Eng-48

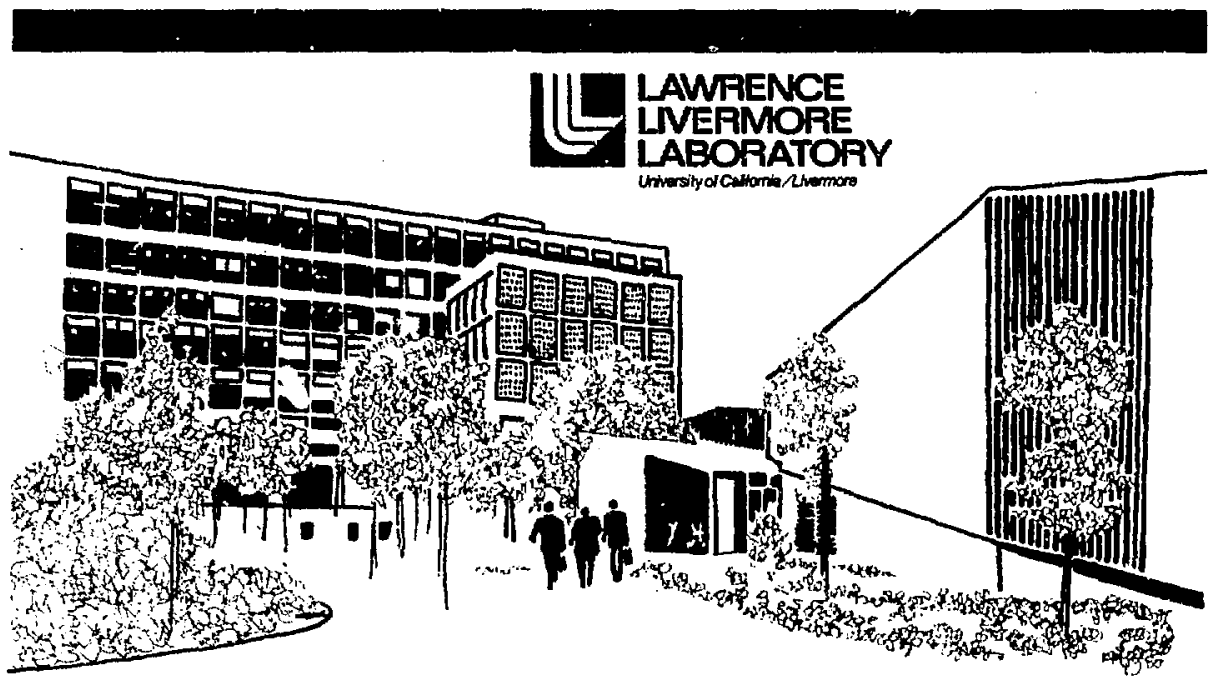




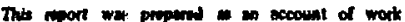
poneored by the Uated Sutes Comenenet. Neither the

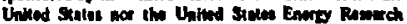
4 Dmopment Adetrimintion, nor any of thetr employen, nor any of theit contrecton, wbontracton,

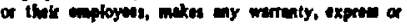

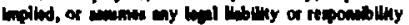

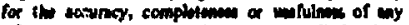

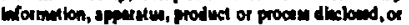
novenals the its un would not tiffire pitritely owned riphls.

\section{Notice.}

Refirence to a company or product anme dou not imply epproval of recominendetion of the product by

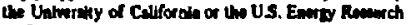
4 Dmopiment Aministration to the exclution of othen that may be aticle.

Printed in the United Stutes of America Aratibble from

National Technical Informalion Service

U.S. Depurtment of Corrmerce

S28s Part Royal Rand

Sptingrield, VA 22161

Price: Printed Copy S : Microflehe $\mathbf{5 2 . 2 5}$

\begin{tabular}{|c|c|c|c|}
\hline Fos hans & $\begin{array}{c}\text { Domentic } \\
\text { Prias } \\
\end{array}$ & Pen neses & 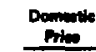 \\
\hline $001-025$ & $\$ 3.50$ & $326-350$ & 10.00 \\
\hline $026-050$ & 4.00 & $351-375$ & 10.50 \\
\hline $051-075$ & 4.50 & $376-400$ & 10.75 \\
\hline $076-100$ & 5.00 & $401-425$ & 11.00 \\
\hline $101-125$ & 5.50 & $426-450$ & 11.75 \\
\hline $126-150$ & 6.00 & $45 i-475$ & 12.00 \\
\hline $151-175$ & 6.75 & $476-500$ & 12.50 \\
\hline $176-200$ & 7.50 & $501-525$ & $12.7 \%$ \\
\hline $201-225$ & 7.75 & $526-550$ & 13.00 \\
\hline $226-250$ & 8.00 & $551-575$ & 13.50 \\
\hline $251-275$ & 9.00 & $576-600$ & 13.75 \\
\hline $276-300$ & 9.25 & 601-up & 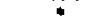 \\
\hline $301-325$ & 9.75 & & \\
\hline
\end{tabular}

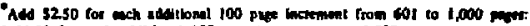
add 4.50 for exch wofitonal 100 pare tecrement oret 1,060 papt. 


\section{LAWFENCE LNEFMOAE LAEOAATOAY}

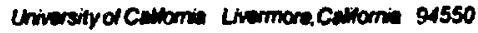

\section{UCRL-52137 \\ A 120-kUV BEAM DIRECT CONVERSION SYSTEM FOR TFTR INJECTORS}

G. W. Hamilton

MS. date: September 21, 1976 


\section{Contents}

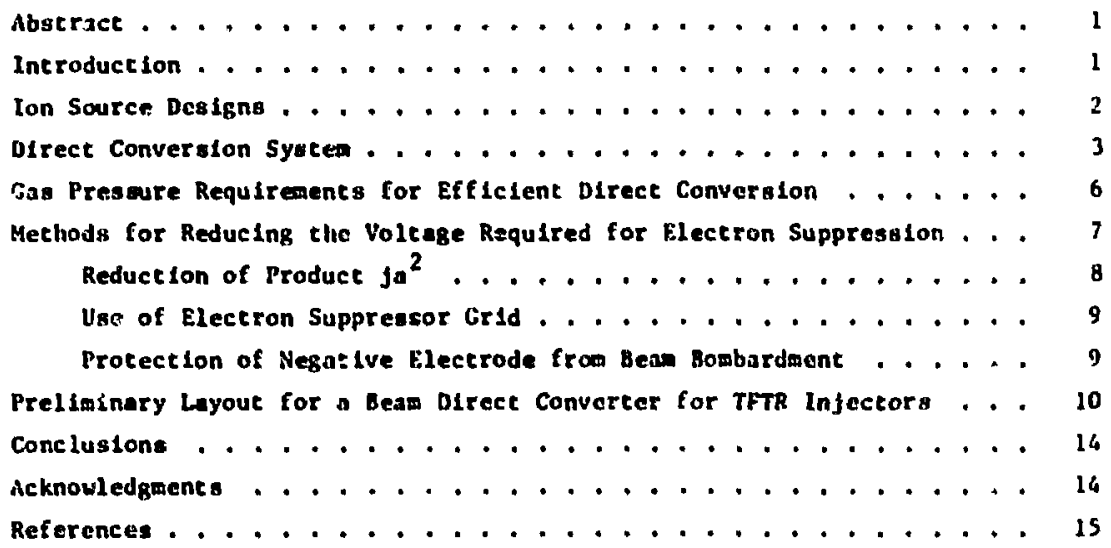




\title{
A 120-keV BEAM DIRECT CONVERSION SYSTEM FOR TFTR INJECTORS
}

\begin{abstract}
Seveval practical nutivations exist for the development of beam direct conversion syatems that are compatible with the injection systems of large experiments such as the Tokatak Fusion Tes: Reactor (TFTR). We present a preliminary design in which we analyze the most acute problems anvolind in ocaling up existing dosigns and apparatus to fulfill TFTR requirements. Sume of the questions addressed are the requirements for electron suppresston, gas pupping, compactness, and power densities, A new Idea 1s presented that allows for the handling of higher beas power. The gross savings in the capital cost of injector power supplies for the TFTR w111 be about $\$ 7.2$ alilion, but the net savings w111 be sowewhat less than this. This prelisinary design has not yet revealed fundamental imitations with respect to the development of beam energy-recovery systems operating at high levels of current, voltage, and power densities.
\end{abstract}

\section{Introduction}

Several practical motivationg exist for the development of bean direct convarsion systcas ${ }^{l}$ that are coxpatible with the high-energy injection systens of large experiments such as the Tokanak Fusion Teat Reactor (TFTR) : ${ }^{2}$

- Savings in capital cost. Destgns of large experiments such as TFTR and $\mathrm{HX}^{3}$ are noranlly liwited by the capital cost, of which a agnificant fraction is the cost of power supplies for the high-voltage injector. A subsantial saving in capttal cost is possible if the power can be reduced by 30 to $70 \%$ by recovering the energy of the residual charged beara rather than deflecting it to a beas duap.

- Simplification. The high-power beam dump may be simplified if the charged beam is decelerated in the recovery syatem before it is collected.

- Size reduction. It may be pussible to shorten the overall length of the injection systew by eliminating the large sweep magnet and replacing the high-power, charged-beam dump with the direct energy converter. 
For these reasons, we are designing a beam direct converter system suitable for the TFTR infection system, This development is the logical step after the 120-keV experiments we ar: now heginning in the LBL neutralbeam test stand. 4,5

\section{Ion Source Designs}

Ion sources for the TFTR will be developed at both the Lawrence Livermore and Lawrence Berkeley Laboratories (LLL and LBL) and at the Oak Ridge National Laboratory (ORNL). In each Instance, the ion sources will be optinized to emit a 50- to 80-A total beam (mostly $D_{1}^{+}$) at energies of $120 \mathrm{keV}$ or higher. The efficiency of neutralization by electron capture will be a maximum of 44\% for $120-\mathrm{keV} D_{1}^{+}$or $24 \%$ for $120-\mathrm{keV} H_{1}^{+}$. Eecause of the higher neutralfzation fraction of the slower particles and becalise the beams wt1l be optimized for $D_{1}^{+}$, the half- and third-energy fractions of the residual, charged beams will be only 10 to $20 \%$.

The LBL/LLL TFTR ion source will consist of a rectangular emission area of maximum size $10 \times 40 \mathrm{~cm}$ from which lons will be extracted and accelerated in a slab-shaped beam; the ions will than be partially converted to neutral atoms by electron capture in a neutralizing duct up to $2 \mathrm{~m}$ long. If the beam density at the plasma source is $250 \mathrm{~mA} / \mathrm{cm}^{2}$, the $\mathrm{grid}$ transparency is $60 \%$, and the neutralization fraction is $40 \%$, the density of the residual charged beam will be approximately $90 \mathrm{~mA} / \mathrm{cm}^{2}$. These source characteristics represent a two-fold change in our previous design paraneters for direct conversion systems: the larger charged-beam current per unit width $(0.9 \mathrm{~A} / \mathrm{cm}$ or $11 \mathrm{MN} / \mathrm{m})$, and the higher beam space-charge potential in the reglons not neutralized by electrons.

The ORNL TFTR ion beams differ from the LBL/LLL beams because of their circular shape. A beam of about 50 A w111 be produced in a 25-cm-diam cross section. This implies an average residual charged-beam current density of $61 \mathrm{~mA} / \mathrm{cm}^{2}$, again assuming $40 \%$ neutralization. For purposes of direct conversion, the important difference is in the shape of the beam cross section. 


\section{Direct Conversion System}

A side view of an In-line, beam direct converter ${ }^{1,4}$ is shown in Fig. 1 . To be compatible with TFTR injectors, the neutralizing cell must be at ground potential; the collection electrode must be at positive high vol:sge $+\mathrm{V}^{+}$ (about +100 to $+110 \mathrm{kV}$ ); and the electrcos produced in the neutralizing cell must be repelled by a negative $h i g h$ voltage $-y^{-}$applied by negative electrodes before and after the positive collection electrode.

The most acute problem arising from the requirements presented by the TFTR ion sources is the suppression of electrons produced within the neutralizing chamber so that they are nit. collected at posicive high voltage by the collection electrode. The potential profiles applied by these collection electrodes, including the effect of beam space charge, are shown in Fig. 2 for the LBL/LLL design. Figure 2(a) shows tine longitudinal profile (2); Fig. $2(b)$ shows the traverse proflle $G(x)$ near the first negative electrode, at the position indicated in $\mathrm{Ftg}$. 1 as Section A-A. Figure 2(b) shows a slabshaped beam of thickness a $=10 \mathrm{~cm}$ passing betweeil two electrodes to which the negative high voltage $\mathrm{V}^{-}$is being applied. To avold bombardment of the negative electrodes by the beam, the spacing b between the negative electrodes must be larger than thickness a.

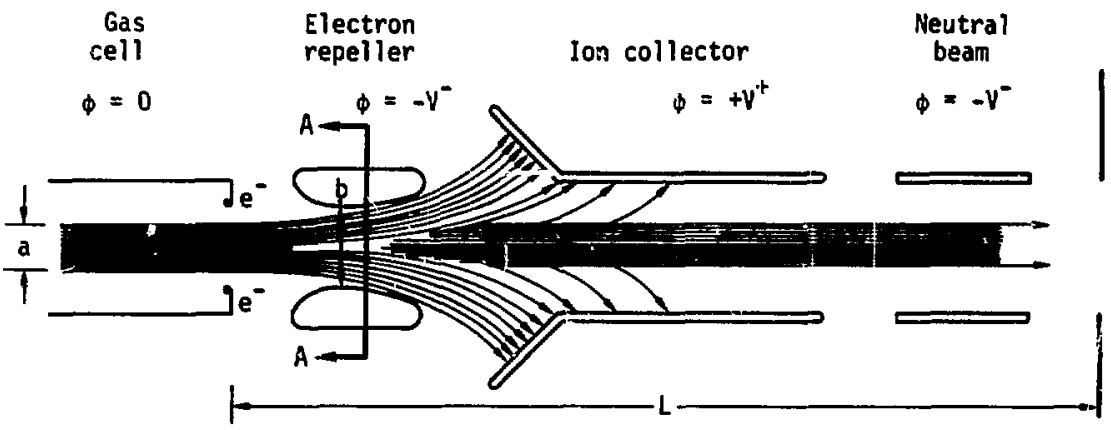

Fig. 1. Space-charge-controlled direct converter. The dimensions $a$, $b$, and $L$ are defined in the text. Section A-A indicates the location of the transverse potential profile $(x)$ shown by Fig. $2(b)$. In this verston, the neutralizing cell is at ground potential, and the potentials of the positive and negative electrodes are $+v^{+}$and $-v^{-}$, respective!y. 
If the beam dimensions arj assumed infintte in the $y$ ard $z$ directions, and if the beam density $\mathrm{J}$ is uhiform, the potential profile can se computed from Gauss's Law:

$$
d^{2} \phi / d x^{2}=-J / E_{0} v
$$

For a boundary condition $0=-y^{-}$at $x= \pm b / 2$, the potential profile within the beam $(|x| \leq a / 2)$ is

$$
\phi(x)=j a^{2} / 8 \varepsilon_{0} v\left(2 b / a-1-4 x^{2} / a^{2}\right)-v^{-} .
$$

Outside the beam $(a / 2 \leq|x| \leq \mid \jmath / 2)$,

$$
\phi(x)=j a / 4 \varepsilon_{0} v(b-2 x) \cdot \cdot v^{-} .
$$

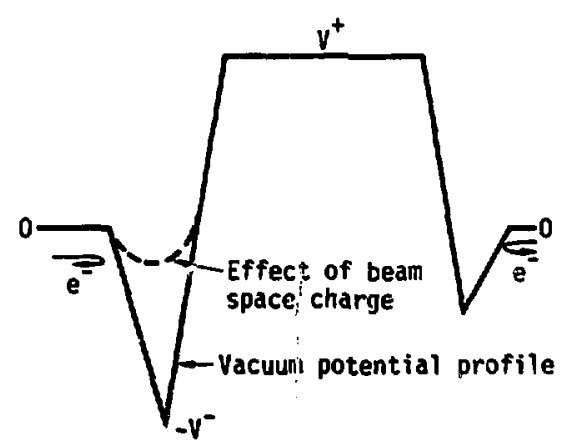

(a)

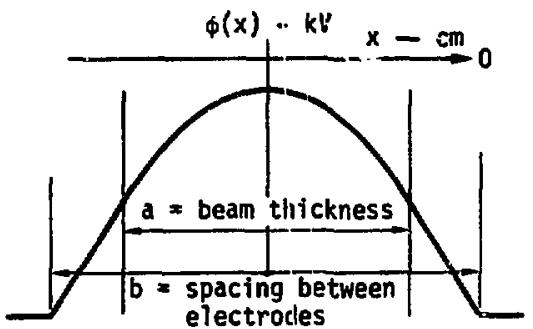

(b)
Suppression of electrons originating at che pocential 0 - 0 requires that $g(x)<0$ for all values of $x$. That 1s, for a slab-shaped beam,

$$
v^{-}>j a^{2} / 8 \varepsilon_{c} v(2 b / a-1)
$$

$>75 \mathrm{kV}$ for LBL TFTR condftions.

F1g. 2. Longltudiasl and transverse potential profiles in a beam direct energy converter. (a) Longitudinal potential profile $\phi(z)$, including the negative potentials required to prevent electrons from being cullected at positive $h / g h$ voltage. (b) Transverse potential profile $\phi(x)$ at Bection A-A (see FIg, 1), where $\phi=-V^{-}$at $x= \pm b / 2$. The effect of beam space charge reduces the negative potential barrier as shown. 
For a cylindrical beam of equal current, electron suppression is an even more severe problem. If the beam radius is a and the electrode radius is b, the negative voltage required to suppress the electrons for a circular bean $1 \mathrm{~s}$

$$
v^{-}>j a^{2} / 4 \varepsilon_{0} v(1+2 \ln b / a)
$$

For ORNi TFTR conditions,

$$
\mathrm{v}^{-}>150 \mathrm{kV}
$$

Because of voltage-holding problems and power consumption by the negative electrode, such large negative voltages are not desirable. The negative electrode draws current via two agencies: the collection of positive lons produced In the background gas; and the secondary electrons emitted by the interception of some fraction of the half-energy beum component. We must therefore consider several means of reducing the negative voltage required to sunpress the electrons produced within the neutralizing chamber:

A portion of the power consumption is proportional to the beckground gas pressure; therefore, if the gas pressure 1s sufficiently low, this portion of the power consumption will be negligible.

- The negative voltage may be reduced by reducing the product ja ${ }^{2}$ (if this reduction is compatible with TFTR specifications).

- The negative voltage may be reduced by substituting a long, transparent grid for the solid electrode silown in Fig. $10^{6}$

- Bombardment of the negative electrodes by the Ion beam must be avolded. The suppresso: electrode must be shaped to avold interception of a large fraction of the half-energy component. The electrode shape should be designed so that the secondary electrons $\mathrm{H}_{11}$ bis coliected at ground potential and not at positive high voltage. The ion source could be designed to leave shadows in the beam where nonintercepting electrodes could be located.

In the following sectlons of this paper, we shall discuss each of these possibilities. 


\section{Gas Prsssure Requirements for Efficient Direct Conversion}

The most critical gas ressure requirement placed on a direct conversion system is imposed by the power load resulting from the accelisutian and collection of the slow lons and electrons produced by ionization and charge exchange of the background gas. The resulting emission of secondary alectrons at negative high voltage must also be considered. Ocher gas-prissure considerations auch as voltage-holding requirements are less critical than the power load.

The power load due to the above effects. must be negligible compared to the power of the charged beam, $\mathrm{I}^{+} \mathrm{V}^{+}$, where the energy of the charged beam is almost equal to $h=$ positive electrode voltage $v^{+}$. If an lon-alectron pair produced by Iontzation of a gas molecule is acceleraced to a total energy of $\left(\mathrm{V}^{+}+\mathrm{V}^{-}\right)$, the power load w111 be

$\left[I^{+} n_{g k s} L\left(\sigma_{10}+\sigma_{10 n_{1}+}\right)+I^{0} n_{g a s} L \sigma_{10,}, 0\right]\left(V^{+}+V^{-}\right)(1+\varepsilon) \ll I^{+} V^{+}$,

where $n_{\text {gas }}$ is the background gas density, and $L$ is the effective length of the direct conversion system (see Fig. 1). The cross sections for slow-ion production by charge exchange and by tonization by fast lons and fast neutrals are, respectively, $\sigma_{01}$, $\sigma_{\text {font' }}$ and $\sigma_{101,}, 0^{*}$ The coeffictent for secondary electron emission $E$ may be about 1 .

The inequality (S) is slightly conservative with respect to the power load due to charge exchang: uecause no free electrons are Involved in charge exchange.

For an equilibrium bean emerging frok the leutralizer, $I^{0} \sigma_{01}=I^{+} \sigma_{10}$, where $\sigma_{01}$ is the cross section for re-ionization of fast neutrals. Therefore, $\mathrm{I}^{+}$and $\mathrm{I}^{0}$ cancel from the inequality. The gas pressure can be computed as follows:

$n_{8 a g^{L}}\left(\sigma_{10}+\sigma_{10 n, t}+\frac{\sigma_{10}}{\sigma_{01}} \sigma_{\text {ion }} 0\right) \ll \frac{v^{+}}{\left(v^{+}+v^{-}\right)(1+\varepsilon)}$. 
The relevant cross sections ${ }^{j}$ for 120 -kel $\mathrm{D}^{+}$ions are the following:

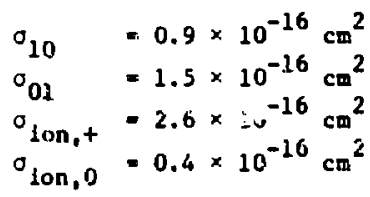

Thus,

$$
\left(\sigma_{10}+\sigma_{\text {ion, },}+\frac{\sigma_{20}}{\sigma_{01}} \sigma_{\text {ion, }, 0}\right)=3.74 \times 10^{-16} \mathrm{~cm}^{2} .
$$

If $\mathrm{V}^{+}-120 \mathrm{kV}, \mathrm{V}^{*}$ is a uns adum of $100 \mathrm{kV}$, and the coefficient $\mathrm{E}$ is the maximum of 1.0, the right side of Inequality (6) has a minimun value of 0.273 . Therefore, $n_{g a s} \mathrm{~L}<7.3 \times 10^{14}$ molecules/cm ${ }^{2}$. If the effective length of the direct conversion system is about $100 \mathrm{~cm}$, the gas density is ngas $7.3 \times 10^{12}$ molecules $/ \mathrm{cm}^{3}$, or $\mathrm{p} \ll 2 \times 10^{-4}$ Torr.

This density is sat isfled by the gas pressures computed for elther the TFTR beam line (about $4 \times 10^{-6}$ Torr) ${ }^{2}$ or the system on the LBL high-volitage test stand ${ }^{5}$ (a maximun of $3.5 \times 10^{-5}$ Torr). In both designs, a diffierential pumping stage will be Installed between the high-pressure i eutralizing cell and the low-pressure, direct conversion system. If the systems operate as designed, it will be posstble to use negative electrode voltages as large as $-100 \mathrm{kV}$ without excessive power $10 \mathrm{ss}$ and without voltage breakdown. This statement implies the assumption that the half-energy beam component will be collected separately and that it will not cause an additional power loss.

Us:ng the appropriate cross sections, we have experimentally verifled this computation using a 12-keV $\mathrm{H}^{+}$beam. In the $\mathrm{t} / \mathrm{st}$, we ircreased the background gas pressure up to $5 \times 10^{-4}$ Tort while measuring the sower loading of the negative electrodes. The increase in power load was consistent with inequality (5).

\section{Methods for Reducing the Voltage Required for Electron Suppression}

Although it may be possible to apply a negative voltage of $75 \mathrm{kV}$ or more to suppress electrons, we prefer to reduce this voltage. This can be done by redicing the bean thickness, by using a grid to suppress only those 
electrons in an outer sheath, or by subdividing the bean while protecting the negative electrode from being bombarded by the beam.

$$
\text { REDUCTION OF PRODUCT } \mathrm{ja}^{2}
$$

Inequality (3) shows that the $\mathrm{V}^{-}$can be reduced by reducing the value of etther $\mathrm{f}$ or $\mathrm{a}$. Because the voltage is proportional to $\mathrm{ja}^{2}$, it is more profitable to reduce a than to reduce $j$.

In a slab-shaped beam system, the most straightforward solution is to restrict the beam thickness a to a value compatible with energy recovery and to increase the length of the source module to provide aufficient extraction area. It has been proposed that the rhickness of the LBL/LLL beam be reduced from $10 \mathrm{~cm}$ to $8 \mathrm{~cm}$ for a different reason. This would reduce the $\mathrm{V}^{-}$requirement from $75 \mathrm{kV}$ to $48 \mathrm{kV}$, assuming the ratio $\mathrm{b} / \mathrm{a}$ is maintained at 1.5 .

Another way to reduce the beam thickness is to subdivide the beam by imersing a nonintercepting negative electrode within the beam. This option is shown by Fig. 3, which also shows the shielding required to protect the negative electrode from beam bcmbardment. By subdivision, the beam thickness a can be reduced by a factor of 2 , thereby reducing the required $\mathrm{V}^{-}$from $75 \mathrm{kV}$ to $19 \mathrm{kV}$ if the ratio $\mathrm{b} / \mathrm{a}$ is not changed. This appears to be practical if the negative electrode can be shielded from beam bombardment (see next section).

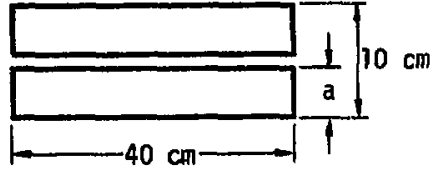

(a)

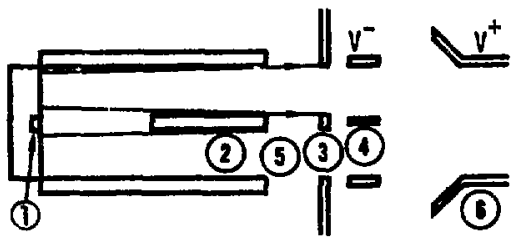

(b)
Fig. 3. Subdivision of a beam to reduce the thickness a (not to scale). (a) End view of a 1040-cm emission area, subdivided to reduce the effective beam thickness a, (b) Side view of a subdivided beam, showing partitions in (1) the plasma source, (2) the neutralizing duct, (3) the groundpotential electrode, and (4) the negative electrode. High-power beam bombardment is avolded by this series of partitions. Also shown are the plenum (5) for differential pumping and the collector electrode (6). 
Raimbault ${ }^{6}$ has computed that the negative voltage requirement can be greatly reduced by a long, cylindical suppressor grid designed to suppress tixe electrons only in an outer boundary layer. By doing this, the beam can be made to expand and pass through the grid layer by layer as it propagates within the long grid. In principle, this system will work for any beam current or beam dimenstons if the suppressor grid to long enough. For a cylindrical system similar to that of the ORNL TFTR system, Rafmbault has computed that the electrons w111 be suppressed by a 1-m-long grid at a potentlal of only $-16 \mathrm{kV}$. However, power loading on the grid must be kept below the level ( $100 \mathrm{~W} / \mathrm{cm}^{2}$ for gteady state) at which thermionic emissiun begins. Although this may be a severe 1imitation, the system deserves further study for TFTK application.

\section{PROTECTIUN OF NEGATIVE ELECTRODE FROM BEAM BOMBARDMENT}

Subdivision of the beam into thinner sections requires a negative electrode immersed in the beam. To avoid emission of secondaxy and/or thermionic electrons at negative high voltage, it is essential that the negative electrode be protected from beam bombardment. It is possible to install a series of partitions to ensure that the immersed negative electrode is shielded from the beam. FIgure 3(a) shows how the lon beam may be so partitfoned to shield the immersed negative electrode.

Bombardment of surfaces at ground potential or above may be tolerable because the resulting secondary electrons are not serlous un.less they are accelerated. However, it is not possible to install a shield directly in the high-power beam, which has an average power density $\left(18 \mathrm{~kW} / \mathrm{cm}^{2}\right)$ that exceeds the heat-transfer IImitations for a water-cooled surface. To shield the negative electrode, the beam must be partitioned at the source and a series of partitions must be installed in the neutralizer and pumping plenum.

Figure 3 shows how the extraction grid can be partitioned within the plasma source before the beam is extract d. The $1 / \mathrm{e}$ beam divergence in the direction parallel to the slit grids is only $\pm 0.5^{\circ}$ in the LBL $20-\mathrm{keV}$ sources; therefore, we expect the divergence to be only $\pm 0.2^{\circ}$ when suct - beam is accelerated to $120 \mathrm{kev}$. The beam will thus spread out by only about $\pm 3.5 \mathrm{~mm}$ as it travels $1 \mathrm{~m}$ through the neutralizer. The density of the beam power 
depositad on the walls of the partition w1ll be small because of the grazing incldence. The power density depostted on the side wall will be approximately equal to the beam power density $\left(18 \mathrm{~kW} / \mathrm{cm}^{2}\right)$ multiplied by the tangent of $0.2^{\circ}$ (1.e., $63 \mathrm{Wicm}^{2}$ ).

Because the partition in the neutralizing cuct will also Impede the flow of gas through the duct, it wili be possible to increase the average gas pressure in the duct and to shorten the neutralizer.

\section{Preliminary Layout for a Beam Direct Converter for TFTR Injectors}

Figures 4, 5, and 6 show a preliminary layout for a beam direct converaion system compatible with the LBL/LLL TFTR Injectors. Figuis 4 shows
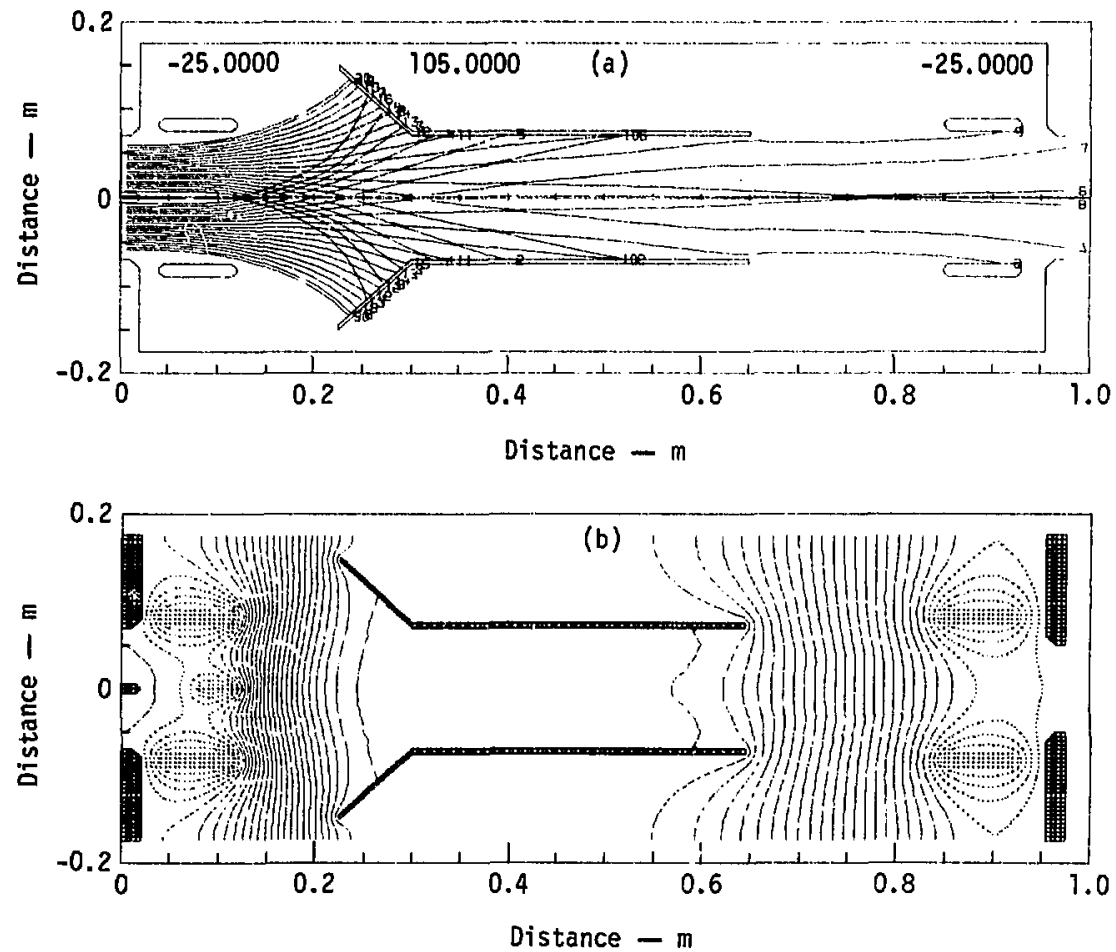

Fig. 4. Trajectories (a) and potential contours (b) for a subdlvided energy recovery system consistent with TFTR requirements, as computed by the DART code. 


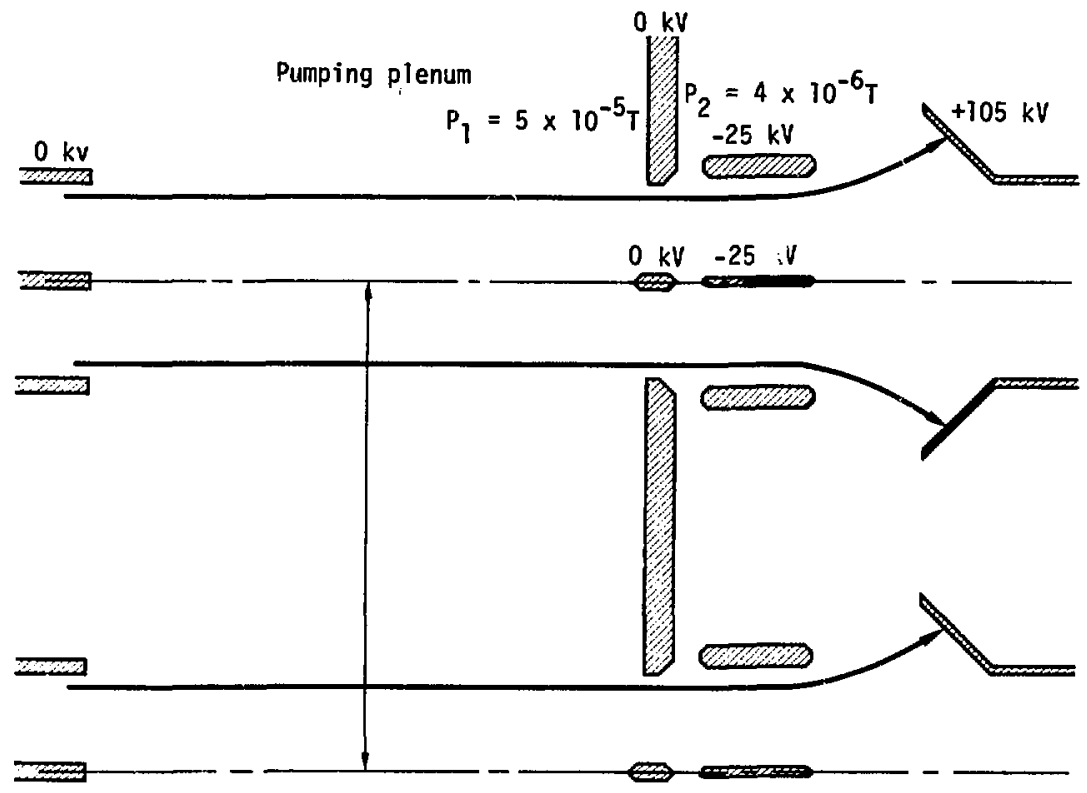

207

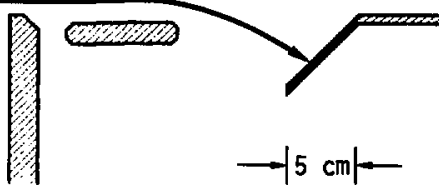

Fig. 5. A layout of the subdivided system shown schematically by Fig. 3, drawn to scale to fit the dimensions of the TFTR beam lines and consistent wh the trajectory computation of Fig. 4. This system occupies the space intended for a large sweep magnet and charged beam dump, both of which will be replaced by the direct conversion system.

the trajectories and potential contours computed by the DART $\operatorname{code}^{8}$ for a system in which the slab-shaped beam is subdivided by an immersed negative electrode at a voltage of $-25 \mathrm{kV}$. The system collects $95 \%$ of the full-energy beam at a potential of $+105 \mathrm{kV}$, which implies a power efflctency of $83 \%$ for recovery of this component. Raising the collector voltage does not improve the efficiency because the immersed negative electrode perturbs the beam 
$+120-k V, 60-A$

ion source

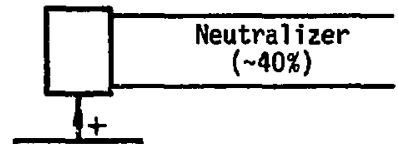

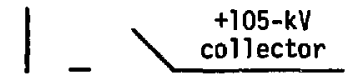

$5 \mathrm{kV}$

$60-A$

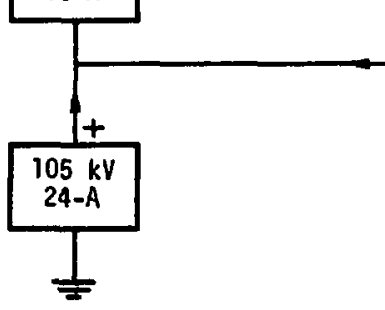

24-A neutral beam
36-A

recovered

charged beam $+120-k V, 60-A$ ion source

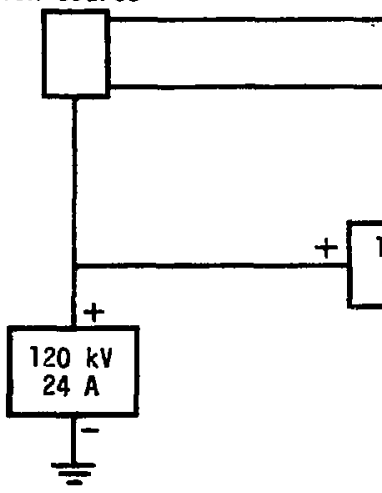

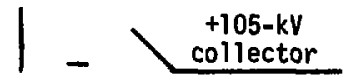

24-A neutral beam

Fig. 6. Two examples of circuits to recirculate the recovered energy to supplement the acceleration power supply of the ion scurce. In both designs, the total power supply requirement is $4.15 \mathrm{MW}$, assuming $40 \%$ neutralization efficiency for $120-\mathrm{kV} \mathrm{D}$. Compared to the total beam requirement of $60 \mathrm{~A}$ at $120 \mathrm{kV}$, the gross saving in acceleration power supplies is 3.05 $\mathrm{MW}$ (assuming 70\% overall efficiency of beam direct conversion). 
optics. The net efficiency is actually sonewhat lower than $83 \%$ because of the power consumed by electrons, half-energy lons, and the regative electrodes.

Figure 5 shows how such a system could be Installed in the beam line now being designed for TFTR injectors. 2 The direct converter system would occupy the space now required for the large sweep magnet and the chargedbeam dumps. At this position, after one stage of differential pumping, the gas pressure is predicted to be only $4 \times 10^{-6}$ Torr. The direct converter systems are sufficiently compact that adjacent beams can be installed at $35-\mathrm{cm}$ intervals, a spacing that is consistent with the existing TFTR design.

Figure 6 shows two examples of power supply systems that could feed back the recovered energy to supplement the high-voltage power supplies for the Ion source. These power supplies, which may be the most expensive components of the injection system, could thereby be upgraded to extract a total beam perhaps twice as large as the current capacity of the rectifiers without direct conversion. Beam-energy recovery could therefore be used either to economize on the capital cost of power supplies or to iucrease the total beam using existing power supplies.

If we assume that the overall efficiency of charged beas energy recovery 1s $70 \%$ and the neutralization efficlency is $40 \%$, the total power supply requirement in each of the examples of Fig. 6 is $4.15 \mathrm{~mW}$. Because of its higher neutralization efficiency, the half-energy charged beam will be not mure than 10 to 20\%. This effect is included in the $70 \%$ overall efficiency of direct conversion, and is not otherwise indicated in the simplified diagrams of $\mathrm{Flg}_{8}$. 6. In comparison with the total beam power of $7.2 \mathrm{NW}$, these examples represent a saving of $3.05 \mathrm{NW}$ for each injector, each of which supplies $2.9 \mathrm{~m}$ of neutral-bean power.

Tweive such injectors $w 111$ be required to furnish 34 IN of neutral-beam power for the TFTR. If the capital cost of power supplies is $\$ 200 / \mathrm{kW}$, the savings provided by the use of beas direct conversion will be $\$ 7.2$ million. The savings will be sonewhat reduced by the cost of installing the reccvery systens and will be increased by elinlnating the large sweep agnet: and beam dups for the charged beans. 


\section{Conclusions}

We find that the requirements for direct conversiun of the residual. charged team of injectors programed for large experiments such as TFTR represent an advance over present designs and that these requirements can probably be fulfilled by any of several techniques. One solution is to reduce the beam thickness from $10 \mathrm{~cm}$ to $8 \mathrm{~cm}$ or less. Another possibility is to employ the new idea presented in this paper, namely, the addition of an extra negative electrode to suppress electrons. Our preliminary designs indicate feasibility with respect to the increased beam densities and beam areas profected for TFTR. Some of the questions addressed are the requirements for electron suppression, gas pumping, compactness, and power densities. The motivations for development of beam direct conversion systems for such applications are the economies in capital cost, diaposal of the charged beam at a very high power density, and the savings in space by elimination of the large sweep magnets and charged-beam dumps.

This preliminary design has not yet revealed fundamental ifmitations with respect to development of conversion systems operating at even higher levels of current, voltage, and power densities.

\section{Acknowledgments}

Consultations with W. L. Barx and R. W. Moir were invaluable in this study. DART code computations were conducted by C. E. McDowe11. Compat1bility with TFTR injector requirements was assured by consultations with the neutral-beam groups at LLL, LBL, and ORNL. 


\section{References}

1. D. J" Bender, W. L. Barr, and R. W. Molr, "Performance Analysis of In-Line Direct Converters for Neutral Beam Sources," in Proc. Sixth Symp. Engineering Problems of Fusion Research, San Diego, California, 1975 (IEEE) p. 184.

2. TFTH Neutral Beam Injection System Conceptual Design, Lawrence Berkeley Laboratory, Rept. LBL-3296 (1975).

3. F. H. Coensgen, MX Hajor Project Proposal, Lawrence Livermore Laboratory, Rept. LLL-Prop-142 (1976).

4. W. L. Barr and R. W. Moir, "A Review of Direct Energy Conversion for Fusion Reactors," in Proc. Second Topical Meeting on the Technology of Controlled Thermonuclear Fusion, Richland, Washington, 1976 (ANs, in preparation).

5. J. M. Haughian, W. R. Baker, L. A. Blag1, and D. B. Hopkins, "Test Facility for the Development of 150-keV Multi-Megawat Neutral Beam System" in Proc. Sixth Symp. Engineering Problems of Fusion Research, San Diego, California, 1975 (IEEE 1976), p. 53.

6. P. RaImbault, "In IIne Electrostatic Energy Recovery System for Fast Neutral Particle Injectors without Beam Interception," Ceatre d'Estudes Nucleaires de Fontenay-aux-Roses, Rept. EUR-CEA-FC-823 (1976).

7. H. Tawara and A. Russek, "Charge Changing Processes in Hydrogen Beams," Rev. Mod. Phys. 45, 178 (1973).

8. B. C. Howard, W. L. Barr, and R. W. Molr, DART: A Simulation Code for a Direct Energy Converter for Fusion Reactori, Lawrence LIvermore Laboratory, Rept. UCRL-51557 (1974). 